\title{
Working Around the Problem: The Impact of Being Overweight and Obese on the Treatment of Clinical IIIness
}

\author{
Sarel Brand, ${ }^{a}$ Linda Brand, ${ }^{b}$ De Wet Wolmarans ${ }^{b *}$ \\ a Unit for Environmental Sciences and Management, North-West University, Potchefstroom, South Africa \\ ${ }^{b}$ Center of Excellence for Pharmaceutical Sciences, North West-University, Potchefstroom, South Africa \\ *Corresponding author, email: dewet.wolmarans@nwu.ac.za
}

\begin{abstract}
Overweight and obesity are not only two highly prevalent conditions in the South African society, but they also contribute to 6 of the 10 most common causes of death. Further, being overweight not only results in significant metabolic and endocrine disturbances, it also changes how patients respond to most pharmacotherapeutic interventions for clinical illness. The present paper will attempt to elucidate some of the most common physio-pathological phenomena associated with being overweight and obese. We will briefly focus on the manner in which especially excessive visceral adipose tissue contributes to an altered physiological state and pharmacokinetic profile, while highlighting important clinical aspects of comorbid conditions that are frequently observed in this patient cohort.
\end{abstract}

\section{Introduction}

Confronted with the reality of an overweight and progressively obese society, clinicians are faced with one of the most serious medical dilemmas in modern history. In fact, 6 of the 10 most common causes of death in South Africa, ${ }^{1}$ three of which rank second, third and fourth, can be caused, exacerbated or complicated by being overweight. ${ }^{2-4}$ They are diabetes mellitus type 2, cerebrovascular-related diseases, heart diseases not related to cerebrovascular incidents, hypertension, chronic lower respiratory diseases, and ischaemic heart disease. Applying body-mass index (BMI) as a rough guide only, an overweight adult will present with a BMI of more than 25, while an obese adult will nominally have a BMI of greater than $30 . .^{5}$ In children under 5 years of age, a weight-for-height value greater than 2 standard deviations above the World Health Organization (WHO) Child Growth Standards (CGS) median classifies as being overweight, while obesity is diagnosed if said value is greater than 3 standard deviations above the WHO CGS median. ${ }^{5}$ Based on these criteria, the South African prevalence of overweight and obesity, respectively, is considerable reason for concern (Table 1).
Although the treatment of overweight and obesity is a crucial first step in the prevention and treatment of secondary comorbidities, clinicians are increasingly faced with an overweight society in need of medical attention for conditions that may not necessarily be related to being overweight or obese. That said, having a higher than normal BMI contributes significantly to changing the clinical profile of patients and how they respond to therapeutic intervention. The current paper will therefore attempt to highlight key aspects of relevance with respect to the general principles that must guide clinical approaches to overweight and obese patients. Not focusing on the treatment of obesity per se, we will address the following areas of interest:

- How being overweight affects a normal physiological and pharmacokinetic profile, especially concerning aspects that can influence drug action and that are markedly affected by obesity; and

- Common comorbidities and secondary pathologies and how best to approach them in primary practice.

Table 1 - Percentages of the South African population that are overweight and obese, respectively Adapted from 6

\begin{tabular}{|c|c|c|c|}
\hline & $\%$ Overweight & $\%$ Obese & World Obesity Ranking \\
\hline \multicolumn{4}{|c|}{ Men } \\
\hline Adults & 41 & 15 & \multirow{2}{*}{105} \\
\hline Boys and Adolescents & 20 & 10 & \\
\hline \multicolumn{4}{|c|}{ Women } \\
\hline Adults & 65 & 40 & \multirow{2}{*}{18} \\
\hline Girls and Adolescents & 29 & 13 & \\
\hline
\end{tabular}


Species aside, being overweight or obese changes almost everything else

\section{A matter of location - visceral adipose tissue and the simulation of nutrient overload}

Excessive adipose tissue changes the physiological functioning of the human body in several ways, none of which are advantageous.7 Importantly, visceral (i.e., abdominal) adipose tissue, and not so much lower body or subcutaneous fat, is reason for concern. ${ }^{8,9}$ Indeed, whereas excessive visceral body fat is associated with an increased risk of metabolic complications, e.g., diabetes, heart disease, and dyslipidemia, increased lower body fat mass carries no such risk. ${ }^{9}$ Moreover, waist circumference, in most instances an accurate measure of abdominal fat mass, is a better predictor of metabolic complications than BMI. ${ }^{10}$

Visceral adipose tissue contributes in a distinctly different manner from subcutaneous adipose tissue in altering the physiological processes of the human body. Not only is abdominal fat more lipolytically active than subcutaneous fat due to its higher expression of noradrenergic receptors, it is also resistant to the anti-lipolytic effects of insulin. ${ }^{11}$ This, together with its significant capacity to convert inactive cortisone to active lipolytic cortisol, results in a constant release of free fatty acids in the systemic circulation. ${ }^{11}$ Although metabolic responses to a constant elevation in free fatty acid concentrations differ between patients, ${ }^{12}$ accelerated processes of lipolysis can in simple terms be equated to a nutrient overload, as even when they are fasting, overweight and obese patients present with high free fatty acid levels. This phenomenon paves the way for noteworthy physiological consequences as free fatty acids and other nutrients must either be utilised in processes of growth or energy expenditure, or be stored. Considering that the adipose storage capacity in overweight and obese patients is already under significant pressure, and that visceral fat is prone to accelerated processes of lipolysis, free fatty acids for which there is no storage space in adipose tissue are unavoidably stored in non-adipose tissues. ${ }^{13}$ These include skeletal muscle cells, hepatocytes, capillary endothelium, and pancreatic $\beta$-cells. As these tissues are not suitable for the storage of triglycerides, a range of adaptive and maladaptive processes, i.e., systemic inflammation, are triggered; these in turn contribute to and exacerbate metabolic complications, e.g., insulin resistance and cardiovascular disease. ${ }^{14}$

\section{Excessive adipose tissue adds another, not so friendly, endocrine organ}

Adipocytes, especially abdominal cells, function as a collective endocrine organ that releases several hormones and cytokines into the blood stream. ${ }^{14}$ In a lean adult that has in the order of 35 billion adipocytes, each containing $0.4-0.6 \mu \mathrm{g}$ of triglycerides, these molecules function to regulate and maintain body energy stores. ${ }^{7}$ However, in overweight and obese patients who may present with up to 125 billion adipocytes which can store up to $1.2 \mu \mathrm{g}$ triglycerides per cell, the endocrine functions of fat cells may have significant deleterious effects. These include an inability to feel satiated, the development of hormonal disturbances, e.g., hirsutism, anovulation, and insulin resistance, as well as pathological neuroinflammatory processes. Table 2 briefly summarises the likely physiological sequelae in overweight and obese patients resulting from the excessive secretion of hormones and cytokines by adipose tissue.

\section{Adipose tissue - the architect that redesigns body compartments}

The human body broadly consists of hydrophilic aqueous and lipophilic fatty compartments. ${ }^{26}$ Generally, lipophilic compounds, e.g., steroid and thyroid hormones and lipid soluble drugs, will demonstrate a greater volume of distribution and a longer halflife in patients with a higher adipose mass, compared to those with a greater lean mass, while the opposite is true for most hydrophilic molecules, e.g., peptide hormones, catecholamines, and water-soluble drugs. ${ }^{27}$ Following release or administration, endogenous molecules and drugs are distributed to target tissues via the blood stream. As most compounds only exert clinical effect in their free forms, i.e., when they are not bound to

Table 2 - Adipose tissue as an endocrine organ

\begin{tabular}{|c|c|}
\hline Hormone & Physiological Effect in Overweight and Obese Patients \\
\hline Leptin & - Excessive levels of leptin are associated with leptin resistance and an inability to feel satiated. ${ }^{15,16}$ \\
\hline Resistin & - Increased levels of resistin are associated with insulin resistance, hyperglycemia and type 2 diabetes mellitus. ${ }^{17}$ \\
\hline Adiponectin & $\begin{array}{l}\text { - Lower rates of adiponectin secretion are found in obese patients; however, this is associated with insulin } \\
\text { resistance, hyperinsulinemia and type } 2 \text { diabetes mellitus. }{ }^{18}\end{array}$ \\
\hline Estrogens & $\begin{array}{l}\text { Increased levels of estrogens in obese patients result from inherent expression of P450 aromatase in } \\
\text { adipocytes, in this case especially those located in the lower body }{ }^{19} \text { - aromatase converts androgenic } \\
\text { precursors to estrogen; } \\
\text { - Physiological impact includes gynecomastia in men }{ }^{20} \text { and anovulation, dysfunctional menstrual bleeding and } \\
\text { polycystic ovary syndrome in women. }{ }^{21}\end{array}$ \\
\hline Androgens & $\begin{array}{l}\text { - Increased conversion of weak androstenedione to potent testosterone; }{ }^{22} \\
\text { - Physiological impact includes hirsutism, anovulation and polycystic ovary syndrome in women. }{ }^{22}\end{array}$ \\
\hline Tumor Necrosis Factor- $a$ & $\begin{array}{l}\text { - Increased levels, though not detectable in plasma assays, have several paracrine effects, including interference } \\
\text { in insulin signaling. }{ }^{23}\end{array}$ \\
\hline Interleukin-6 & $\begin{array}{l}\text { - Excessive IL- } 6 \text { production results in insulin resistance, systemic inflammation, pancreatic } \beta \text {-cell degeneration, } \\
\text { and hyperglycemia. }{ }^{24}\end{array}$ \\
\hline $\begin{array}{l}\text { Plasminogen Activator } \\
\text { Inhibitor-1 }\end{array}$ & $\begin{array}{l}\text { - Elevated levels, driven by increased IL-1, estrogen, TNF- } a \text {, and insulin increase the risk for thromboembolism, } \\
\text { and myocardial infarction. }{ }^{25}\end{array}$ \\
\hline
\end{tabular}


plasma carrier proteins or organ tissues, homeostatic control over endogenous substances is exercised based on the concentration of the unbound, free fraction in plasma, and not the fraction of the compound harbored in organs, tissues and the paracellular space. Changes in body composition can affect such regulatory processes in several ways. For instance, although some exceptions exist, lipophilic hormones and drugs that distribute into and are stored in adipocytes and other lipid-containing intracellular spaces will not only exhibit a longer half-life but will also take longer to reach a physiologically and therapeutically adequate steady state free fraction. To the contrary, most water-soluble compounds, e.g., peptide hormones and polarised drugs will, following release into the blood stream, exhibit shorter half-lives and reach steady state quicker in overweight or obese patients, compared to patients with a larger aqueous compartment. Another example of how changes in body composition may alter the pharmacokinetic properties of compounds can be found in altered plasma protein concentrations. Indeed, albumin, ${ }^{28}$ sex hormone binding globulin ${ }^{7}$ and thyroid hormone binding globulin ${ }^{29}$ increase in obese patients and may result in a slower onset but longer duration of drug action as well as longer half- lives. It suffices to say that changes in the ratio between the relative percentages of adipose and aqueous compartments, will yield distinctly different physiological and pharmacotherapeutic outcomes in different individuals. Table 3 summarises some of the most common phenomena from a therapeutic perspective in this regard.

\section{Common comorbidities in overweight and obese patients of relevance for primary practice}

As highlighted in Section 1, overweight and obese patients represent a large cohort of the South African society and clinicians will increasingly be challenged to treat medical conditions in these individuals. Moreover, it is likely that patients in this category that seek medical attention for specific common conditions, e.g., colds and flu, will either covertly or overtly present with other weight-related comorbidities. Although the treatment of these comorbid conditions must primarily be addressed by weight loss, this section will focus on some of the most common conditions that directly result from the bolstered endocrine capacity of excessive adipose tissue.

Table 3 - A summary of pharmacokinetic modifications in overweight and obese patients

\begin{tabular}{|c|c|}
\hline Parameter altered & Physiological and pharmacotherapeutic impact \\
\hline Steady state & $\begin{array}{l}\text { - Steady state of lipophilic drugs, e.g., sex steroids and narcotics, will be delayed; however, it will not be affected as } \\
\text { much following missed doses as in patients with a lower adipose mass. }\end{array}$ \\
\hline Onset of action & $\begin{array}{l}\text { - Onset of action may be delayed for lipophilic drugs, e.g., opioids and benzodiazepines; if rapid relief is needed, } \\
\text { loading doses should be calculated based on total body weight. }\end{array}$ \\
\hline Duration of action & $\begin{array}{l}\text { - Due to its larger volume of distribution in obese compared to lean patients, lipophilic drugs will remain in the body } \\
\text { for longer. As such, drugs may elicit a pharmacological or toxicological response for longer than anticipated. } \\
\text { - Importantly! As most compounds function within a narrow therapeutic window with respect to the circulatory } \\
\text { free fraction, it is unlikely that the slow release of drugs by fat stores will be sufficient to maintain an adequate } \\
\text { therapeutic response. Steady state of lipophilic compounds is reliant on the equilibrium reached between the } \\
\text { plasma protein bound and unbound drug fractions, respectively. However, in the event of drug withdrawal, a new } \\
\text { state of equilibrium will be reached between the amount of drug stored in adipose tissue, and the concentrations } \\
\text { released into the circulatory system. This process is, however, not only dependent on drug concentrations but can be } \\
\text { affected by other factors, including diet changes, exercise, and cardiovascular function. } \\
\text { - Therefore, although some exceptions exist where this phenomenon is applied to a therapeutic advantage, i.e., oral } \\
\text { isotretinoin or topical estrogen for dermatological conditions, it is highly unlikely that adipose stores of lipophilic } \\
\text { drugs will contribute significantly to their therapeutic effect. }\end{array}$ \\
\hline Efficacy & $\begin{array}{l}\text { Efficacy is defined within the context of drug administration. For example, in the case of acute conditions, e.g., pain, } \\
\text { analogous doses administered in lean and overweight patients, respectively, will elicit markedly different responses. } \\
\text { However, where drug action is not related to acute conditions or where rapid increases in drug concentration are not } \\
\text { needed, as is the case with high-dose glucocorticoids, efficacy will be less affected in overweight, compared to lean, } \\
\text { patients. }\end{array}$ \\
\hline Toxicity & $\begin{array}{l}\text { As referred to above, fat stores of drugs will not necessarily contribute to maintaining an adequate therapeutic } \\
\text { effect. However, they may contribute significantly to drug toxicity. In the case of amiodarone, a highly lipophilic } \\
\text { antiarrhythmic drug that can be stored in adipose tissues for weeks after its administration, clinically significant } \\
\text { thyroidal and mucosal inflammation can ensue drug withdrawal. Also, isotretinoin, a highly teratogenic compound } \\
\text { used in the treatment of acne, can exert such effect for months after discontinuation. Therefore, as such residual } \\
\text { drug effects can occur for longer in overweight and obese, compared to lean, patients due to the depot effect, great } \\
\text { caution must be applied in such scenarios. }\end{array}$ \\
\hline $\begin{array}{l}\text { Therapeutically important } \\
\text { fluctuations }\end{array}$ & $\begin{array}{l}\text { Under certain circumstances, fluctuations in endogenous molecules or exogenously administered drugs are } \\
\text { important to facilitate therapeutic action. For example, most physiological functions related to sex hormone } \\
\text { physiology, i.e., ovulation and menstruation, are dependent on rapid changes in hormone concentration. Further, } \\
\text { successful treatment of related pathologies, e.g., amenorrhea, menorrhagia, and anovulation, depend on the same } \\
\text { principles. For example, in the treatment of amenorrhea, high dose progesterone is administered for 7-10 days, } \\
\text { followed by rapid, sudden withdrawal. Only then is the response in prostaglandin synthesis and neuroendocrine } \\
\text { activation of the hypothalamus sufficient to induce menstruation and trigger gonadotropin releasing hormone } \\
\text { (GnRH) release, respectively. In overweight and obese patients, such rapid fluctuations in the concentrations of } \\
\text { lipophilic compounds are masked, leading to related pathologies and inadequate treatment responses in most } \\
\text { patients. }\end{array}$ \\
\hline
\end{tabular}




\begin{abstract}
Fact Box for Clinical Practice: Metabolically Normal Obesity
As opposed to the majority of obesity cases in which marked metabolic disturbances, e.g., insulin resistance, dyslipidemia, and elevated blood pressure, are observed, approximately 25-32\% of patients present with no such symptomology. ${ }^{31}$ Attempts to elucidate this phenomenon resulted in the finding that metabolically normal obese patients, though presenting with equal percentages of body fat, have less visceral and hepatic fat stores, but more subcutaneous and peripheral fat deposits ${ }^{32,33}$. These patients, that in some cases have been followed and monitored for up to 11 years, ${ }^{34}$ did not present with elevated risks for cardio-metabolic pathology, compared to lean controls. In contrast, metabolically complicated patients, lean or obese, presented with a 4- to11-fold increased relative risk for diabetes mellitus type 2, compared to metabolically normal individuals of average weight. ${ }^{35}$ These findings highlight the importance of not overly simplifying approaches to specific cohorts of patients.
\end{abstract}

\section{Comorbid conditions in men}

\section{Gynecomastia}

Gynecomastia manifests in adult men due to various underlying pathologies or treatments that either increase or potentiate the effect of oestrogen, or decrease or inhibit the effect of testosterone. ${ }^{36}$ In overweight and obese men, gynecomastia results from increased conversion of androgenic precursors to oestrogen (Table 2). Apart from surgical procedures to remove excess breast tissue, pharmacological options can also be considered. However, if conspicuous symptoms have been present for longer than 1 year, pharmacological intervention is unlikely to be effective. That said, some pharmacological options have shown demonstrable efficacy during the initial proliferative phases of breast development. These are summarised in Table 437,38:

\section{Comorbid conditions in women}

\section{Hirsutism}

Hirsutism, i.e., excessive hair growth in areas that are usually not hairy, e.g., on the face, is a clinical manifestation of the accelerated adipose synthesis of androgenic hormones (Table 2) and may be a significant problem in some overweight and most obese women. Normally, obesity-related hirsutism will be associated with other symptoms of masculinisation, e.g., acne, deepening of the voice, amenorrhea, clitoral hypertrophy, and increased muscularity. ${ }^{39}$ Treatment is directed at either bolstering estrogenic stimulation, or inhibiting androgenic stimulation, or a combination of both. Appropriate strategies are listed in Table $5 .{ }^{40}$

Table 4 - Drugs recommended for the treatment of gynecomastia Important - none of the listed drugs are registered for use in gynecomastia; they are however used off-label.

\begin{tabular}{|c|c|c|}
\hline Drug & Dose & Notes \\
\hline $\begin{array}{c}\text { Tamoxifen } \\
\text { Kessar / Novadex- } D^{\circ} / \text { Tamoplex }^{\circ} / \text { TamoxiHexal }^{\circ} \\
\text { /Neophedan }\end{array}$ & $20 \mathrm{mg}$ per day for 3 months & $\begin{array}{l}\text { Adverse effects, including deep vein } \\
\text { thrombosis are relatively uncommon }\end{array}$ \\
\hline $\begin{array}{c}\text { Anastrazole } \\
\text { Arimidex }^{\circ} / \text { Accord-Anastrazole }^{\circ} / \text { Everdex }^{\circ} / \text { Mylan- } \\
\text { Anastrazole }^{\circ} / \text { Stradexa }^{\circ}\end{array}$ & $\begin{array}{c}1 \mathrm{mg} \text { per day for } 3 \text { months depending on the } \\
\text { therapeutic response }\end{array}$ & $\begin{array}{l}\text { Adverse effects are uncommon. However, } \\
\text { monitor for renal and hepatic disease }\end{array}$ \\
\hline $\begin{array}{c}\text { Letrozole } \\
\text { Femara }^{\circ} \text { / Accord-Letrozole / Cipla-Letrozole } \\
\text { Laradex } / \text { /Trozolt }\end{array}$ & $\begin{array}{c}2.5 \mathrm{mg} \text { per day for } 3 \text { months depending on the } \\
\text { therapeutic response }\end{array}$ & Adverse effects as for anastrazole \\
\hline $\begin{array}{l}\text { Exmestane } \\
\text { Aromasin }\end{array}$ & $\begin{array}{l}25 \mathrm{mg} \text { per day for } 3 \text { months, depending on the } \\
\text { therapeutic response }\end{array}$ & Adverse effects as for anastrazole \\
\hline
\end{tabular}

Table 5 - Drugs recommended for the treatment of hirsutism

\section{Drug / Formulation Dose}

As treatment is indicated in overweight to obese patients, ethinyl estradiol doses should not be lower than $30 \mu \mathrm{g}$ per day but should also not exceed $35 \mu \mathrm{g}$
Combination Oral

Contraceptives

Ginette / Marvelon / Yasmin

Femodene $E D^{\circ} /$ Nordette

\section{Notes}

- Progestin components can either be androgen-neutral e.g., gestodene, levonorgestrel, norgestrel, or desogestrel, or anti-androgenic, e.g., drosperinone, cyproterone, dienogest;

- Can be augmented with up to $50 \mathrm{mg}$ cyproterone (see below) from day 1-21 of the active tablets;

- Adverse effects and contra-indications to be monitored and considered are related to the risk for deep vein thrombosis. Overweight to obese patients are especially at risk and need to be followed up every three months. Avoid use of COCs especially in women with a history of deep vein thrombosis, those presenting with migraine accompanied by prodromal aura, or in women who smoke more than 10 cigarettes per day.

- In women with an established and regular menstrual cycle: Initially, 10-50 mg per day from day 5-14 of the menstrual cycle, titrated upwards to a maximum of $100 \mathrm{mg}$ if no clinical response is observed within 3 months;

Cyproterone

Androcur / Cipla-Cyproterone / . In anovulatory women presenting with
Cyproplex Cyproplex amenorrhea and irregular bleeding, $10-50 \mathrm{mg}$ per day, titrated upwards to a maximum of $100 \mathrm{mg}$ per day if no clinical response is observed within 3 months.
Most common adverse effects include vaginal xerosis and decreased libido
Spirinolactone

Aldactone / Spiractin / SandozSpirinolactone
Avoid. See "Fact Box for Clinical Practice: The Jekyll-and-Hyde Personality of Spironolactone" 


\section{Fact Box for Clinical Practice: The Jekyll-and-Hyde Personality of Spironolactone}

Spironolactone is predominantly an aldosterone receptor antagonist $t^{4}$ and is used in the treatment of cardiovascular disease as a potassium sparing diuretic. However, it has long been known that administration of spironolactone in adult men and premenopausal women can cause significant endocrine disturbances related to both masculinisation in women and the development of female characteristics in men. ${ }^{41-43}$ As such, research has demonstrated that spironolactone most likely acts as a partial agonist on a range of steroid hormone receptors, including the glucocorticoid, androgen, and oestrogen receptors. ${ }^{27,44}$. The effects of all partial agonists are dichotomous in that they can elicit either an agonistic or antagonistic response, depending on the concentration of the endogenous ligands present. Thus, in men who normally present with high endogenous testosterone but low oestrogen levels, spironolactone will most likely express antagonistic properties, producing a softening of the voice and gynecomastia. However, in women who normally present with high oestrogen but low testosterone levels, spironolactone will often induce symptoms related to virilisation, including hirsutism and anovulation.

The use of spironolactone in women presenting with hirsutism is applied from the perspective that such patients already present with lower than normal oestrogen and higher than normal testosterone. Thus, the effect observed should be akin to that observed in men. Although this strategy has proved successful in numerous patients, ${ }^{41}$ the effects of spironolactone are intricately linked to physiological parameters, e.g., local concentrations of sex steroids in specific tissues, that its effect is unpredictable and inconsistent. For this reason, it is advised that women with symptoms related to virilisation rather be treated with more potent antiandrogenic compounds.

\section{Anovulatory menstrual bleeding}

Anovulatory menstrual bleeding describes any form of menstrual bleeding occurring in the absence of a normal ovulatory response and that is unrelated to uterine pathology. ${ }^{45}$ Etiologies may include, among other, polycystic ovary syndrome (PCOS), hyperprolactinemia, thyroid disorders, and premature ovarian failure. ${ }^{46}$ The menstrual bleeding occurring in patients with anovulation is in fact not related to the normal hormonal changes associated with follicular development, but rather results from endometrial proliferation in response to the low, but relatively constant estrogenic stimulation of the endometrium. As very little progesterone is secreted to counter such proliferation, the endometrial tissue breaks down unpredictably and uncontrollably, resulting in patients experiencing irregular menstrual periods. ${ }^{46}$ In this instance, such stimulation is brought about by extragonadally derived estrogen, e.g., from adipose or adrenal gland tissue. However, ovarian estrogen from partially developed follicles may also contribute to a stable, although lower, estrogen tone.

The present section will focus on polycystic ovary syndrome for two reasons. First, in most patients, PCOS is closely related to excess weight. Second, PCOS is the most common cause of anovulatory bleeding and infertility in women of reproductive age ${ }^{47}$ and it is therefore likely that clinicians treating overweight and obese female patients will observe and diagnose PCOS at some stage.

Briefly, PCOS is characterised by 2 or more of the following signs and symptoms ${ }^{48}$ :

- Oligo- or anovulation;

- Clinical or biochemical signs of hyperandrogenism;

- Polycystic ovaries, in the absence of other unrelated causes.

Other symptoms that may be present, but for which an accurate diagnosis is not required ${ }^{48}$ are:

- Insulin resistance;

- Impaired glucose tolerance;

- Increased LH levels; and

- Increased LH/FSH ratio.

\begin{tabular}{|c|c|c|}
\hline Drug / Formulation & Dose & Notes \\
\hline $\begin{array}{l}\text { Combination Oral Contraceptives } \\
\text { Diane- } 35^{\circ} \text { /Minerva-35 / Ginette }{ }^{\circ} / \\
\text { Marvelon / Yasmin } / \text { Femodene ED / } \\
\text { Nordette }^{\circ}\end{array}$ & As for hirsutism (Table 5) & $\begin{array}{l}\text { - Contraceptive therapy is indicated to improve menstrual } \\
\text { irregularities and treat comorbid symptoms of virilism; } \\
\text { - Contraceptive therapy will not improve insulin sensitivity, } \\
\text { nor address issues of infertility; } \\
\text { - Progestin components as for hirsutism (Table 5); } \\
\text { - Adverse effects as for hirsutism (Table 5) }\end{array}$ \\
\hline
\end{tabular}

\section{Metformin}

Glucophage /Sandoz-Metformin / Bigsense / Accord-Metformin / AustellMetformin / Diamin / Gluconorm \% Metforal" / Metformin Alkem / Metphage / Mylan-Metformin / Romidab / Diaphage /Mengen / Metored / Diabetmin ${ }^{\circ}$

\begin{tabular}{|c|c|c|}
\hline $\begin{array}{l}\text { Clomifene } \\
\text { Clomid }^{\circ} \text { / Fertomid }{ }^{\circ} \text { / ClomiHexal }\end{array}$ & $\begin{array}{l}\text { Initiate with } 50 \text { mg per day for } 5 \text { days } \\
\text { on days } 3-5 \text { of the cycle (if present) } \\
\text { or following induction of a menstrual } \\
\text { period; } \\
\text { If no response is observed, titrate } \\
\text { upwards to } 100 \text { mg per day for } 5 \text { days. }\end{array}$ & $\begin{array}{l}\text { Reserve use for specialist supervision. Ovarian } \\
\text { hyper-stimulation may be triggered in which case urgent } \\
\text { medical care must be provided. }\end{array}$ \\
\hline Lifestyle Change and Weight Loss & $\begin{array}{l}\text { Calorie controlled diets are to be } \\
\text { introduced as soon as possible. } \\
\text { - Moderate exercise is advised as } \\
\text { adjunctive therapy. }\end{array}$ & $\begin{array}{l}\text { Weight loss is unlikely to be effective in women of normal } \\
\text { weight and may even exacerbate the condition. Reserve for } \\
\text { patients with a BMl of }>22 \mathrm{~kg} / \mathrm{m}^{2}\end{array}$ \\
\hline
\end{tabular}

- Especially advised in patients with established impaired glucose tolerance, impaired fasting glucose or diabetes mellitus type 2 . upwards to $1000 \mathrm{mg}$ twice per day after 2-3 weeks.
Contraceptive therapy is indicated to improve menstrua Contraceptive therapy will not improve insulin sensitivity,

Progestin components as for hirsutism
Adverse effects as for hirsutism (Table 5 ) 
The term 'polycystic' describes observations of partially developed follicles, usually arranged in the form of a pearl string in the ovaries of patients. Never developing up to ovulatory potential, these follicles encyst and remain in this state ad infinitum. The factors listed above act in concert to yield the clinical syndrome. First, overweight and obese women present with higher androgen concentrations compared to lean individuals (Table 2). Further, they are often insulin resistant, presenting with hyperinsulinemia and impaired glucose tolerance. While androgens suppress follicular development, high levels of insulin increases the LH/FSH ratio. ${ }^{49}$ Consequently, higher levels of $\mathrm{LH}$ drive further androgen synthesis, while lower levels of FSH contribute to inadequate follicular development.

How best to approach PCOS from a therapeutic perspective is still debated..$^{50}$ However, strategies are largely directed at curbing androgen excess, treating menstrual irregularities and secondary symptomologies, e.g., hirsutism, improving insulin sensitivity and losing weight. These are summarised in Table $6 .{ }^{50}$

\section{Fact Box for Clinical Practice: Some Notes on Why We Become} Overweight and Obese and the Role of Calorie Restriction Broadly speaking, obesity is caused by an excessive intake of calories, in relation to energy expenditure over a chronic period of time. ${ }^{7}$ In fact, only minor daily excesses in calorie intake can cause significant increases in adipose mass. For instance, a relative daily excess of only $5 \%$, can increase body mass with $5 \mathrm{~kg}$ within one year only. Over 30 years, a daily excess of only $8 \mathrm{Cal}$ more than utilised, can add $10 \mathrm{~kg}$ of body weight. ${ }^{51}$ Interestingly, genetic predisposition accounts for only $40 \%$ of the changes in the body weight in the average individual. Indeed, the majority of patients suffer from obesity due to poor lifestyles characterised by high caloric diets and inactivity. However, children born from one (or both) obese parents, or children who become obese after the age of 6 years, have a 79\% risk of becoming obese adults. ${ }^{52}$ These findings led to investigations to uncover the role for genetic predisposition in certain susceptible populations. As such, we know today that in a small minority of patients, obesity may indeed have an exclusively genetic basis. Patients presenting with monogenetic obesity, i.e., obesity in which only a single gene mutation is sufficient to trigger an abnormal metabolic response, demonstrate functional mutations with respect to genes that are involved in the functioning of two major endocrine systems, i.e., leptin and corticosteroid signalling. ${ }^{7}$ However, these account for fewer than $1 \%$ of all obesity cases, in which case specialist intervention is paramount. Considering weight loss, patients are often unenthusiastic, misinformed, and unwilling to appreciate the clinical severity of their condition and in taking personal responsibility for their health. Inaccurate and often plain false reporting in the layman's media generally results in the misconception that it is near impossible to shed weight with calorie controlled diets and changes in lifestyle. Although morbidly obese patients will almost never shed sufficient weight only by dieting - these individuals only benefit from bariatric surgery in the long run ${ }^{53}$ - the majority of overweight and obese patients can benefit adequately from calorie restriction. It is broadly advised that patients with a BMI $>25 \mathrm{~kg} / \mathrm{m}^{2}$ reduce their energy intake by approximately $500 \mathrm{Cal}$ per day. Such interference will reduce body weight on average by $0.45 \mathrm{~kg} /$ week and will ensure a reduction of $10 \%$ in the initial body weight, within 6 months. In the event where personalised diets cannot be applied, the following guidelines for reduction in calorie intake have been suggested by the WHO for persons of different weights $^{54}$ :

\begin{tabular}{ll} 
- $68-90 \mathrm{~kg}:$ & 1000 Cal/day \\
- $90-114 \mathrm{~kg}$ & 1200 Cal/day \\
- $114-136 \mathrm{~kg}$ & 1500 Cal/day \\
- $136-160 \mathrm{~kg}$ & 1800 Cal/day \\
- $>160 \mathrm{~kg}$ & 2000 Cal/day \\
\hline
\end{tabular}

\section{Conclusion}

Overweight and obesity are not only two highly prevelant conditions in the South African society, but they also contribute to 6 of the 10 most common causes of death. Further, being overweight not only results in significant metabolic and endocrine disturbances, it also changes how patients respond to most pharmacotherapeutic interventions for clinical illness. This paper attemped to elucidate some of the most common physiopathological phenomena associated with being overweight and obese that may influence pharmacotherapy. We briefly focussed on the ways in which especially excessive visceral adipose tissue contributes to an altered physiological state and pharmacokinetic profile, while highlighting important clinical aspects of comorbid conditions that are frequently observed in this patient cohort.

\section{References}

1. Santulli G. Epidemiology of cardiovascular disease in the 21 st century: updated numbers and updated facts. J Cardiovasc Dis. 2013;1(1):1-2.

2. Pulgarón ER. Childhood obesity: a review of increased risk for physical and psychological comorbidities. Clinical therapeutics. 2013;35(1):A18-A32.

3. Vest $A R$, et al. Bariatric surgery and cardiovascular outcomes: a systematic review. Heart. 2012; heartjnl-2012-301778.

4. Withrow $D$, Alter $D$. The economic burden of obesity worldwide: a systematic review of the direct costs of obesity. Obesity Reviews. 2011;12(2):131-141.

5. WHO. Overweight and obesity. Fact sheet. 2011(311).

6. WHO. Global status report on noncommunicable diseases 2014: attaining the nine global noncommunicable diseases targets; a shared responsability. In Global status report on noncommunicable diseases 2014: attaining the nine global noncommunicable diseases targets; a shared responsability. 2014.

7. Klein M, Fabbrini E, Romijn JA. Obesity. In Williams Textbook of Endocrinology. Melmed S ed. Elsevier Saunders: Philadelphia; 2011, p.1897.

8. Snijder MB, et al. Trunk fat and leg fat have independent and opposite associations with fasting and postload glucose levels: the Hoorn study. Diabetes Care. 2004;27(2):372-7.

9. Jensen MD. Gender differences in regional fatty acid metabolism before and after meal ingestion. J Clin Invest. 1995;96(5):2297-303.

10. Wang $Y$, et al. Comparison of abdominal adiposity and overall obesity in predicting risk of type 2 diabetes among men. Am J Clin Nutr. 2005;81(3):555-63.

11. Mittelman SD, et al. Longitudinal compensation for fat-induced insulin resistance includes reduced insulin clearance and enhanced beta-cell response. Diabetes. 2000;49(12):2116-25.

12. Chan JC, et al. Diabetes in Asia: epidemiology, risk factors, and pathophysiology. Jama. 2009; 301(20):2129-40.

13. Iyer $A$, et al. Inflammatory lipid mediators in adipocyte function and obesity. Nat Rev Endocrinol. 2010;6(2):71.

14. Karastergiou K, Mohamed-Ali V. The autocrine and paracrine roles of adipokines. Mol Cel Endocrinol. 2010;318(1-2):69-78.

15. Friedman JM. Obesity in the new millennium. Nature. 2000;404(6778):632.

16. Lee $Y$, et al. Liporegulation in Diet-induced Obesity: The Antisteatotic Role Of Hyperleptinemia. J Biol Chem. 2001;276(8):5629-35.

17. Steppan $\mathrm{CM}$, et al. The hormone resistin links obesity to diabetes. Nature. 2001;409(6818):307.

18. Weyer $C$, et al. Hypoadiponectinemia in obesity and type 2 diabetes: close association with insulin resistance and hyperinsulinemia. J Clin Endocrinol Metab. 2001;86(5):1930-5.

19. Wajchenberg BL. Subcutaneous and visceral adipose tissue: their relation to the metabolic syndrome. Endocr Rev. 2000;21(6):697-738.

20. Rosen $\mathrm{H}$, et al. Adolescent gynecomastia: not only an obesity issue. Ann Plast Surg. 2010;64(5):688-90.

21. Ehrmann DA. Polycystic ovary syndrome. New Eng J Med. 2005;352(12):1223-36.

22. Kershaw EE, Flier JS. Adipose tissue as an endocrine organ. J Clin Endocrinol Metab. 2004;89(6):2548-56.

23. Kahn BB, Flier JS. Obesity and insulin resistance. J Clin Invest. 2000;106(4):473-81. 
24. Bastard JP, et al. Adipose tissue IL-6 content correlates with resistance to insulin activation of glucose uptake both in vivo and in vitro. J Clin Endocrinol Metab. 2002;87(5):2084-9.

25. Waki H, Tontonoz P. Endocrine functions of adipose tissue. Annu Rev Pathol Mech Dis. 2007;2:31-56

26. Sheng HP, Huggins RA. A review of body composition studies with emphasis on total body water and fat. Am J Clin Nutr. 1979;32(3):630-47.

27. Brunton LL, Lazo JS, Buxton ILO. Goodman \& Gilman's the pharmacological basis of therapeutics Buch. Buch. New York, NY: McGraw-Hill Medical, 2011.

28. Scaglione $R$, et al. Central obesity and hypertensive renal disease: association between higher levels of $\mathrm{BMI}$, circulating transforming growth factor $\beta 1$ and urinary albumin excretion. Blood Pressure. 2003;12(5-6):269-76.

29. Faix JD, Rosen HN, Velazquez FR. Indirect estimation of thyroid hormone-binding proteins to calculate free thyroxine index: comparison of nonisotopic methods that use labeled thyroxine ("T-uptake"). Clin Chem. 1995;41(1):41-7.

30. Casati A, Putzu M. Anesthesia in the obese patient: pharmacokinetic considerations. J Clin Anesth. 2005;17(2):134-45.

31. Brochu $M$, et al. What are the physical characteristics associated with a normal metabolic profile despite a high level of obesity in postmenopausal women? J Clin Endocrinol Metab. 2001;86(3):1020-5.

32. Karelis AD. Metabolically healthy but obese individuals. Lancet. 2008;372(9646):1281-3.

33. lacobellis $G$, et al. Prevalence of uncomplicated obesity in an Italian obese population. Obesity. 2005;13(6):1116-22.

34. Pratley RE. Gene-environment interactions in the pathogenesis of type 2 diabetes mellitus: lessons learned from the Pima Indians. Proc Nutr Soc. 1998;57(2):175-81.

35. Meigs JB, et al. Body mass index, metabolic syndrome, and risk of type 2 diabetes or cardiovascular disease. J Clin Endocrinol Metab. 2006;91(8):2906-12.

36. Braunstein GD. Gynecomastia. New Eng J Med. 1993;328(7):490-5.

37. 3Braunstein GD. Gynecomastia. New Eng J Med. 2007;357(12):1229-37.

38. McLeod DG, Iversen P. Gynecomastia in patients with prostate cancer: a review of treatment options. Urology. 2000;56(5):713-20.

39. Dunaif $A$, et al. Clinical, biochemical, and ovarian morphologic features in women with acanthosis nigricans and masculinization. Obstet Gynecol. 1985;66(4):545-52.
40. Goodman NF, et al. American Association of Clinical Endocrinologists, American College of Endocrinology, and Androgen Excess and PCOS Society disease state clinical review: guide to the best practices in the evaluation and treatment of polycystic ovary syndrome-part 1. Endocr Pract. 2015;21(11):1291-1300.

41. Young RL, Goldzieher JW, Elkind-Hirsch K. The endocrine effects of spironolactone used as an antiandrogen. Fertil Steril. 1987;48(2):223-8.

42. Corrol P, Michaud A, Menard J. Anti-androgenic effect of spironolactone: Mechanism of action. Endocrinology. 1975;97:52-8.

43. Greenblatt DJ, Koch-Weser J. Gynecomastia and impotence complications of spironolactone therapy. Jama. 1973;223(1):82.

44. Campen TJ, Fanestil DD. Spironolactone: a glucocorticoid agonist or antagonist? Clinical and Experimental Hypertension. Part A: Theory and Practice. 1982;4(9-10):1627-36.

45. Casablanca Y. Management of dysfunctional uterine bleeding. Obstet Gynecol Clinics. 2008;35(2):219-34.

46. Speroff L, Fritz MA. Clinical gynecologic endocrinology and infertility. Lippincott Williams \& Wilkins, 2005

47. Azziz $R$, et al. The prevalence and features of the polycystic ovary syndrome in an unselected population. J Clin Endocrinol Metab. 2004;89(6):2745-9.

48. Tarlatzis $R$, et al. Revised 2003 consensus on diagnostic criteria and long-term health risks related to polycystic ovary syndrome. Fertil Steril. 2004;81(1). PMID 14711538

49. Dunaif A. Insulin resistance and the polycystic ovary syndrome: mechanism and implications for pathogenesis. Endocr Rev. 1997;18(6):774-800.

50. Legro RS, et al. Diagnosis and treatment of polycystic ovary syndrome: an Endocrine Society clinical practice guideline. J Clin Endocrinol Metab. 2013;98(12):4565-92.

51. Rosenbaum M, Leibel R, Hirsch J. Obesity. CAS PubMed Article. New Engl J Med. 1997;337:396-407.

52. Whitaker RC, et al. Predicting obesity in young adulthood from childhood and parental obesity. New Eng J Med. 1997;337(13):869-73.

53. Brolin RE. Gastrointestinal surgery for severe obesity. Nutrition. 1996;12(6):403-4.

54. WHO. Energy and protein requirements: report of a joint FAO/WHO/UNU expert consultation, 1985. 